\title{
Особенности контентного наполнения спортивного телеканала «Матч ТВ»
}

Эмин Гасанов

В статье представлен количественный анализ программного наполнения телеканала «Матч ТВ» в течение первых трех лет вещания (2015-2018). Проведено сравнение с программным наполнением телеканала «Россия 2» в последний год вещания (2015). Определены ключевые изменения в особенностях формирования контента общероссийского спортивного телеканала, выявлены тенденции реформирования эфирной сетки.

Ключевые слова: «Россия 2» и «Матч ТВ», спорт, программа, контентное наполнение, сетка вещания.

@ Гасанов Эмин Салман оглы аспирант кафедры теории и экономики СМИ факультета журналистики МГУ имени М.В. Ломоносова (г. Москва, Россия), emin05693@mail.ru

\section{Введение}

В ноябре 2018 г. закончился период, обозначенный руководством «Матч ТВ» как время становления национального спортивного телеканала (был создан 1 ноября 2015 г.). Три года вещания канала «Матч TВ» дают возможность проанализировать не только первичные изменения в его программной политике по сравнению с телеканалом-предшественником - «Россия 2», но и зафиксировать вектор развития и финальный результат реформирования программной политики электронного средства массовой информации.

Попытки изучить первичные изменения в контентном наполнении в стартовые месяцы вещания «Матч ТВ» предпринимал А.С. Павлов (2016). Он отметил тенденцию на увеличение трансляций спортивных мероприятий по сравнению с телеканалом «Россия 2". При изучении технологического и творческого подходов к формированию контента на «Матч ТВ» исследователи пришли к выводу: по сравнению с «Россией 2" увеличилось количество сотрудников, задействованных в создании аналогичных программ, телеканал нарастил технические мощности, что позволило экспериментировать с формами и форматами подачи информации в эфире (Белик, 2018; Авдюшкина, Аверина, 2019). Ф.О. Волчков, 
исследуя концепцию спортивного телеканала, рассматривает различные кейсы с примерами производимого контента в период с ноября 2015 по ноябрь 2018 г. и отмечает заметные попытки руководства транслировать в эфире больше оригинального контента (Волчков, 2018). Другие исследователи, впрочем, полагают, что такая стратегия является для специализирован ного телеканала экономически нецелесообразной (Долгова, 2017).

Работа по изучению изменения контента телеканала «Матч ТВ» ведется нами в рамках исследования системы отечественного спортивного телевидения. Известно, что одним из ключевых аспектов формирования модели развития телеканала является его программное наполнение (Eastman, Ferguson, 2012; Вартанова, 2003). В условиях меняющегося медиапотребления в России различные телевещатели вынуждены подстраиваться под существующую конъюнктуру медиарынка (Вьюгина, 2016). В данном случае нам необходимо рассмотреть не конкретные кейсы программ и трансляций, а системно проанализировать весь эфир «Матч ТВ» на разных этапах его становления, чтобы выявить особенности его контентного наполнения.

Актуальность изучения изменений в программной политике главного спортивного телеканала страны определяется несколькими обстоятельствами. Во-первых, имелись заявления руководителей ООО «Национальный спортивный телеканал» (правообладателя бренда «Матч ТВ») о том, что программная верстка канала-предшественника «Россия 2» нуждается в доработке и будет изменена. Например, было объявлено, что увеличится количество собственного продукта (здесь и далее под термином «собственные программы» имеются в виду оригинальные программы, не только произведенные телеканалом «Матч TВ», но и любые премьерные эфирные события, которые ранее не использовались ни одним другим вещателем), также о разнообразии спортивных трансляций. Речь шла и о том, что телеканал в шесть раз сократит количество художественных фильмов и сериалов ${ }^{1}$. Таким образом, мы имеем основания рассмотреть в динамике, как были реализованы планы по изменению сетки вещания.

Во-вторых, впервые в современной (постсоветской) российской истории в рамках одного холдинга («Газпром-медиа») было консолидировано почти всё российское спортивное телевидение. Из пятнадцати телеканалов, принадлежащих пяти разным учредителям², было образовано двенадцать ${ }^{3}$. Позже их количество сократили до девяти, для большинства из которых «Матч ТВ» является брендообразующим вещателем. Консолидация различных производящих ресурсов в рамках одной организации является стимулирующим фактором для преобразования контентного наполнения телеканала, наращивания собственного продукта в эфире.

В-третьих, спортивный телеканал перешел из федерального государственного унитарного предприятия (ВГТК) в частный медиахолдинг, изменилась структура собственности компании и, соответственно, экономическая модель вещателя.

\section{Методология исследования}

Временной период изучения программ ной сетки - последний год вещания телеканала «Россия 2» и первые три года вещания «Матч ТВ», то есть с 2015 по 2018 г. Этот промежуток обусловлен тем, что в ноябре 2018 г. завершился этап реформирования и становления данного спортивного телеканала, обозначенный руководством до старта вещания. Чтобы проанализировать, как изменилась программная сетка главного спортивного телеканала страны после создания «Матч ТВ», нами были определены следующие временные рамки исследования: две недели вещания канала 
в сентябре 2015 г. (завершающий этап работы «Россия 2»), в сентябре 2016 г. (конец первого года вещания «Матч ТВ») и в сентябре 2018 г. (завершение реформирования нового телеканала).

Этот выбор обусловлен несколькими факторами. Во-первых, это начало телевизионного сезона, когда верстка предается изменениям с учетом прошлых ошибок, анализа рейтингов канала в различное время прошлого сезона. В данном случае такая выборка позволит нам рассмотреть сетку вещания на старте последнего в истории телесезона на телеканале «Россия 2» и сравнить ее с сеткой вещания «Матч ТВ» в начале первого полноценного сезона. Мы сможем определить основные векторы развития, на которые руководством был сделан упор при формировании новой программной политики. При рассмотрении последнего двухнедельного периода (телеканала «Россия 2») можно будет определить, развились ли намеченные тенденции в формировании контента к концу третьего года вещания.

Во-вторых, как в сентябре 2015 г., так и в сентябре 2016 и 2018 гг. в мире не происходили масштабные спортивные события, которые могли бы радикально скорректировать наполнение эфира. Поэтому в данном случае мы имеем право оценивать эфирные сетки в общем контексте информационной политики телеканалов, а установленные закономерности и выводы будут иметь общий характер для всего телесезона.

В-третьих, в сентябре традиционно начинаются чемпионаты и соревнования по различным видам спорта. Мы можем определить, на какие трансляции канал приобрел права, каким видам спорта отдал предпочтение. Кроме того, в этом месяце формирование и наполнение программной сетки полностью зависят от общей информационной политики телеканала и мало подчиняются внешним факторам, таким как изменение расписания матчей и их сокращение. Например, весной количество трансляций сокращается из-за того, что завершаются чемпионаты, групповые этапы переходят в стадии play-off, где представлено гораздо меньше команд. В этот период труднее определить корпоративные установки и концепцию формирования сетки вещания.

В рамках данной статьи мы провели количественное исследование контентного наполнения спортивного телеканала, не затрагивая пока качественные аспекты. На первом этапе работы мы в минутах за две недели - выразили соотношение различных программ и трансляций по тематике и по жанровой принадлежности. Временной отрезок в две недели позволит нам утверждать с большим основанием, что те или иные программы выходят в эфир регулярно.

На втором этапе мы изучили, как изменилось количество спортивных трансляций в эфире, а также их жанровое разнообразие. Здесь рассматриваемый период определен в четыре недели. Это позволяет получить еще более полную картину. Для изучения были взяты программы передач для московского региона 4 (зона вещания «М»).

В итоге нам удастся установить, каких результатов удалось достигнуть «Матч ТВ» в сравнении с телеканалом-предшественником, чей опыт контентного наполнения был признан неудачным, что и послужило одним из факторов реформирования главного спортивного телевещателя страны.

\section{Результаты исследования}

Поскольку и «Россия 2», и «Матч ТВ» являются круглосуточными телеканалами, общий объем вещания за две недели составляет 20160 мин. Самым заметным изменением в программном наполнении после создания «Матч ТВ» стало значительное увеличение количества спортивных 


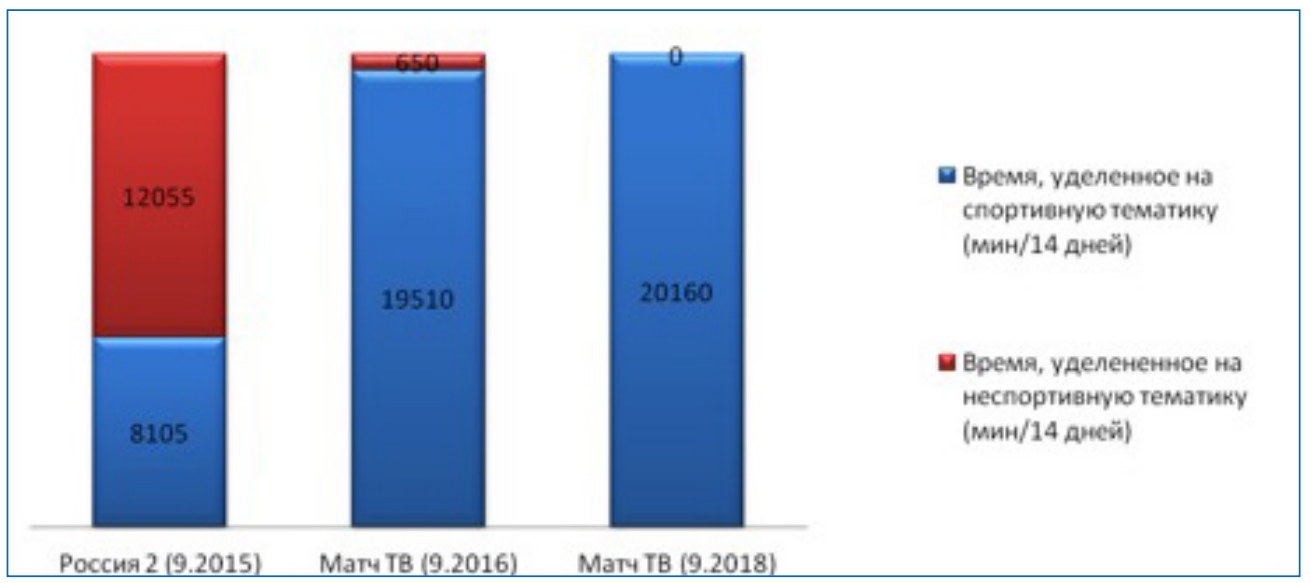

Рисунок 1. Доля спортивных программ на телеканале «Россия 2» и «Матч ТВ» (сентябрь 2015, 2016, 2018 гг.). Источник: tv.mail.ru/moskva/

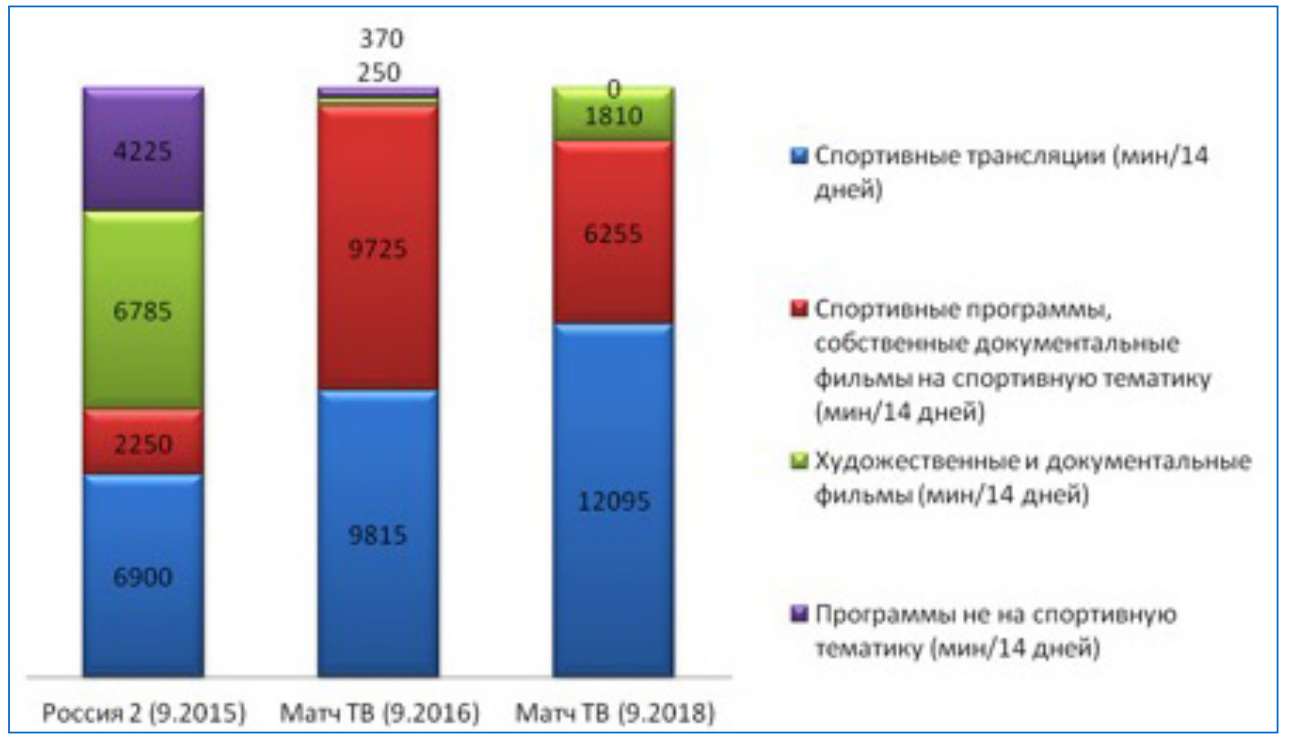

Рисунок 2. Доля программ (по жанрам) на телеканале «Россия 2» и «Матч ТВ» (сентябрь 2015, 2016, 2018 гг.). Источник: tv.mail.ru/moskva/

трансляций и передач, посвященных различным видам спорта. На рисунке 1 мы видим, что телеканал «Россия 2» из 20160 мин. лишь 40\% времени уделил теме спорта. А уже через год «Матч ТВ» увеличил этот показатель более чем в два раза и довел его до 97\%. К 2018 г. из эфира полностью уходят программы не спортивной тематики, показатель спортивных программ и трансляций увеличивается до 100\%. Таким образом, явно прослеживается тенденция на изменение контентной политики вещателя. Из смешанного по тематике телеканала «Россия 2» новый телеканал «Матч ТВ» за три года стал исключительно спортивным.

В 2016 г. на «Матч ТВ» более чем в четыре раза увеличилось количество собственных 
программ и документальных фильмов о спорте по сравнению с последним годом вещания телеканала «Россия 2». Если в 2015 г. они занимали лишь 11,2\% эфирного времени, то в 2016 г. - 48,2\%. Однако этот же показатель в сентябре 2018 г. уменьшился до $31 \%$ (см. рис. 2).

К новостным спортивным программам на телеканале «Россия 2» можно отнести такие проекты, как «Большой спорт», «Большой футбол», «Панорама дня. Life»5. Кроме этого, периодически проходили обсуждения в студии различных спортивных событий с приглашенными гостями. Такие передачи были не регулярными и зависели от того, транслировался ли матч по «России 2» или по «России 1» (главному каналу ВГТРК). Второй вариант применялся активно во время Олимпийских игр и чемпионата мира/Европы по футболу, когда «Россия 1» получала права на трансляцию, а «Россия 2» делала анонсные и аналитические передачи в преддверии матча и после него.

Примером классической новостной программы на «России 2» были проекты «Большой спорт» и «Большой футбол»в зависимости от насыщенности спортивными мероприятиями выходили от одного до трех раз в день. Другая новостная программа «Панорама дня. Life» выходила один раз в день. В ее эфире были представлены видеосюжеты о последних стартах на аренах мира, обзоры важнейших турниров и анонсы соревнований, которые пройдут в ближайшее время. На «Матч ТВ» аналогичной программой является программа «Страна. Life». По воскресеньям на «России 2» выходила аналитическая программа «Большой футбол с Владимиром Стогниенко», на "Матч ТВ» ее аналогом стала программа «После футбола с Георгием Черданцевым».

После начала вещания «Матч ТВ» общее количество собственных новостных спортивных программ увеличилось 6 . Среди них «Все на матч» (аналог «Большого спорта»), «Новости» (спортивные и общественно-политические), «Спортивный репортер», «Культ Тура», «Все на футбол», «Континентальный вечер» (программа о российском хоккее), «Закулисье КХЛ», «Инспектор 30Ж», «Деньги большого спорта», «Лучшая игра с мячом» (о баскетболе) и другие. В первые месяцы вещания «Матч ТВ» на телеканале увеличилось не только количество видов спорта, которым посвящены эфирные события, но также расширилась тематика программ: об экономике спорта, о жизни спортсменов, появились исторические проекты.

В 2018 г. мы наблюдаем оптимизацию разнообразия телепроектов. Из регулярных программ в эфире остались «Новости», «Все на матч», «Континентальный вечер». Вместо цикла «Спортивный репортер» стали выходить специальные репортажи на различные спортивные темы. Появилась еженедельная программа «Реальный спорт» о значимых спортивных событиях недели и «Тотальный футбол» - аналитическая программа с участием экспертов.

Самые частые по периодичности программы на «Матч ТВ» - «Новости» и «Все на Матч» - выходили в 2016 г. в прямом эфире до шести раз в сутки, в зависимости от дня недели. В 2018 г. этот показатель сократился до четырех. Сократилось количество прямых эфиров с участием приглашенных экспертов.

К новостным программам «Матч ТВ» в 2016 г. можно отнести «Спортивный репортер» - ежедневный 20-минутный репортаж. Эта программа сохранилась и в 2018 г., однако изменила название на «Специальный репортаж», увеличился хронометраж до 30 мин. Помимо новостных программ в 2016 г. производители контента на «Матч ТВ» начали прибегать к иным форматам, например, ток-шоу. К ним можно отнести шоу «Культ Тура». Позже проект был закрыт из-за низких показателей рейтинга. В 2016 г. на «Матч ТВ» появились развлекательные 
программы, такие как «Детский вопрос», а так же заменивший в эфирной сетке шоу «Культ тура» проект «Передача без адреса». В 2018 г. он был закрыт, аналогичную программу телеканал запускать не стал.

На телеканале «Матч ТВ» возросло количество документальных фильмов собственного производства: например, в 2016 г. цикл «Кубок войны и мира» о российском хоккее. Каждая серия длится 45 мин., фильм построен на интервью героев, о которых идет повествование, и закадровом тексте. В 2018 г. «Матч ТВ» перестал транслировать собственные документальные фильмы. В эфире стали выходить документальные авторские проекты и развлекательные документальные программы: например, «Десятка», в которой авторы составляют для зрителей различные спортивные рейтинги. Из регулярных документальных циклов отметим проект Кирилла Дементьева «Заклятые соперники», а также программы «Вся правда про...» и «В этот день в истории спорта».

Таким образом, мы видим, что в первый год вещания «Матч ТВ» резко увеличил количество собственного контента, однако в течение трех лет произошла оптимизация как тематическая, так и количественная (по сравнению с последним годом вещания телеканала «Россия 2» показатель вырос на 19,8\%).

В основном это произошло за счет увеличения количества и времени показа спортивных трансляций. Если на телеканале «Россия 2» они занимали 34,2\% эфирного времени, то на «Матч ТВ» в 2016 г. этот показатель повысился до 48,7\%, в 2018 г. он составил 59,9\%. По сравнению с телеканалом «Россия 2» на «Матч ТВ» количество спортивных трансляций выросло на 25,7\%. Мы видим, что обозначенная руководством трансформация программного наполнения телеканала, а именно закупка большего количества спортивных трансляций, была реализована.
С началом вещания телеканала «Матч ТВ» на нем снизилось количество художественных и документальных фильмов несобственного производства. В 2015 г. на телеканале «Россия 2» они занимали 33,6\% эфирного времени. Это были преимущественно сериалы российского производства: «Лорд. Пес-полицейский», «В зоне риска», «Пыльная работа», «Байки Митяя». Кроме этого, транслировались исторические документальные фильмы, такие как «Советская Империя», «Гвардия, мы были просто смертными». Расположение такого контента в эфирной сетке имело хаотичный порядок и не зависело от времени суток или дня недели. Так, в среду 2 сентября 2015 г. начиная с 19:05, то есть в прайм-тайм7 , и до 06:40 утра следующего дня по «России 2» транслировались исключительно сериалы и исторические документальные фильмы.

В 2016 г. на телеканале «Матч ТВ» художественные и документальные фильмы несобственного производства стали занимать лишь 1,2\% времени. Но в 2018 г. этот показатель вновь вырос до 9\% эфирного времени. Однако теперь вещатель, в отличие от «России 2», который транслировал художественные фильмы, закупает фильмы, так или иначе затрагивающие тему спорта или околоспортивную тематику. Например, художественный фильм «Поверь» (ночной эфир, суббота, 15 сентября 2018 г.). Это история футболиста, который из-за совершенной серии краж попадает под уголовное преследование. Тренер пытается спасти главного героя. Он берет процесс тренировок футболиста под личный контроль. В данном случае тема спорта затрагивается отчасти. Однако стоит отметить, что в исследуемом двухнедельном промежутке из 14 транслируемых за это время художественных фильмов нет ни одного, в котором тема спорта бы не затрагивалась. То есть телеканал вновь вернулся к формату закупки контента, что, возможно, обусловлено соображениями 


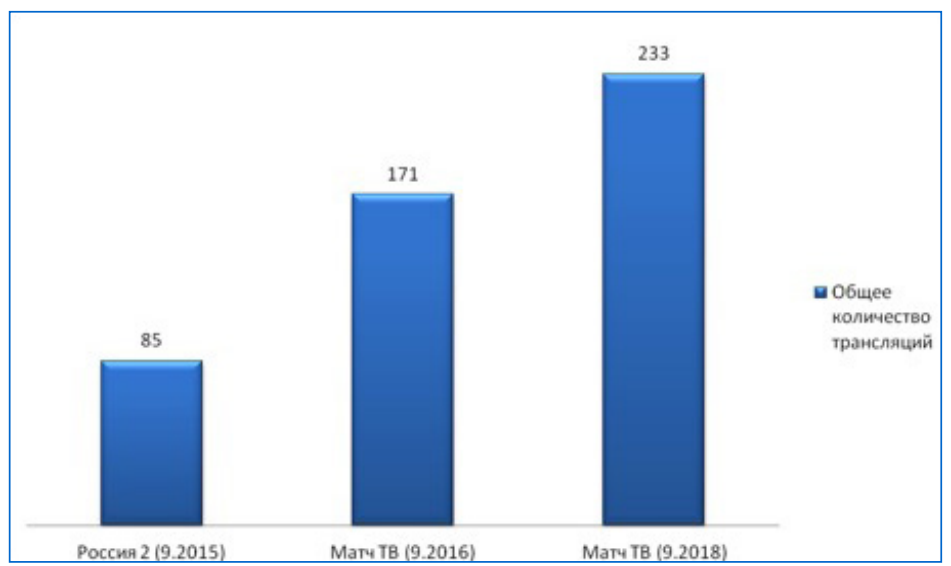

Рисунок 3. Общее количество трансляций на телеканале «Россия 2» и «Матч ТВ» (сентябрь 2015, 2016, 2018 гг.; четыре недели). Источник:: tv.mail.ru/moskva/

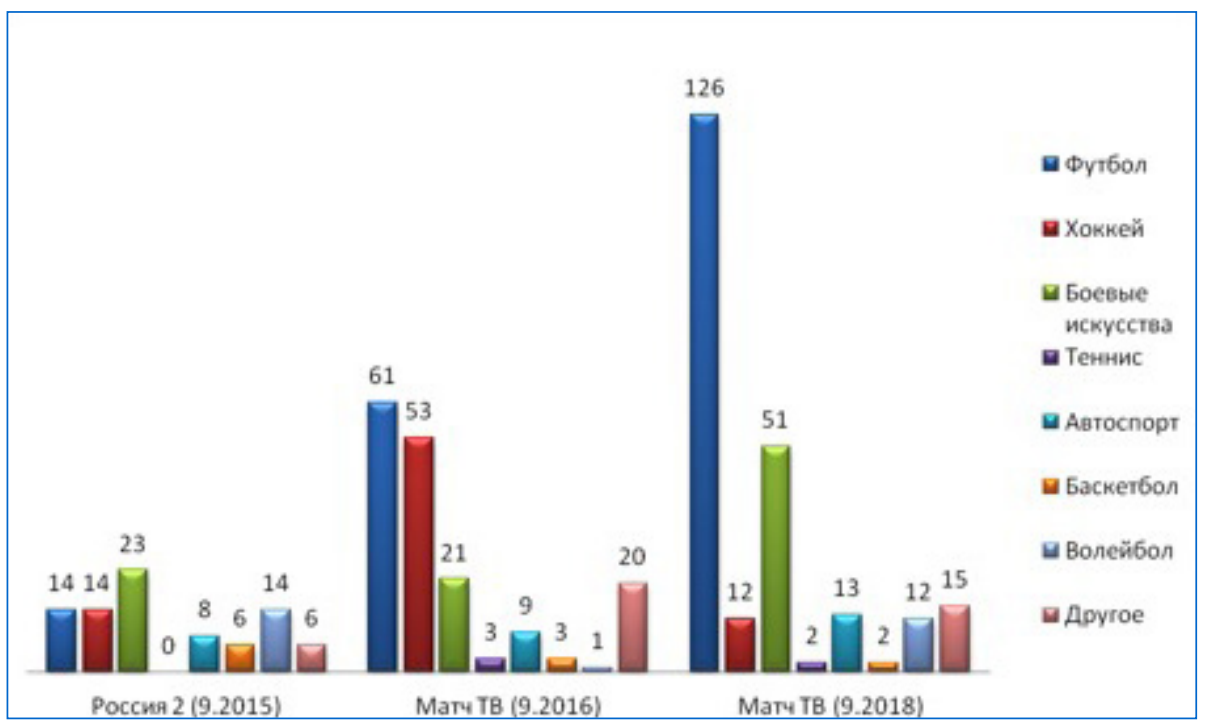

Рисунок 4. Количество трансляций (по видам спорта) на телеканале «Россия 2» и «Матч ТВ» (сентябрь 2015, 2016, 2018 гг.; четыре недели). Источник: tv.mail.ru/moskva/

экономической целесообразности. Однако ключевым различием в данном случае является то, что транслируемые художественные фильмы не нарушают тематическую направленность телеканала.

Явный лидер по наполнению эфира в 2018 г. - спортивные трансляции (см. рис. 3). В 2015 г. на телеканале «Россия 2» в эфире было показано 85 спортивных мероприятий, а уже в 2016 г. «Матч ТВ» более чем в два раза увеличил этот показатель (171 трансляция за четыре недели). К 2018 г. показатель вырос еще на 36\% ( 233 трансляции). «Матч ТВ» по сравнению с "Россией 2» заметно увеличил количество освещаемых чемпионатов, кубков и первенств, то есть расширил разнообразие трансляций по видам спорта (см. рис. 4). Это может быть 
продиктовано как учетом аудиторных предпочтений россиян, так и контекстом общемировых тенденций, когда крупные спортивные вещатели направляют средства на покупку трансляций в большее количество видов спорта (Evens, Iosifidis, Smith, 2013).

Количество футбольных матчей с 14 трансляций в сентябре 2015 г. выросло почти в четыре раза за один год (61 трансляция). В 2018 г. этот показатель увеличился еще более чем в два раза (126 трансляций). Кроме этого, расширилась география спортивных мероприятий: на «Матч ТВ» регулярно транслируются матчи европейских и южноамериканских чемпионатов, кубки континентов, чего не было на «России 2». В данном случае мы с большой долей вероятности можем утверждать, что произошло увеличение затрат на закупку прав на футбольные трансляции, что не раз подтверждали руководители «Матч ТВ».

Ситуация с хоккейными трансляциями имеет иную динамику. За четыре недели в сентябре 2015 г. на телеканале «Россия 2» было показано 14 матчей, в 2016 г. на «Матч ТВ» - 53 матча. Но в 2018 г. «Матч ТВ» значительно сократил показы хоккейных матчей - до 12 трансляций. Несмотря на количественное сокращение, на «Матч ТВ» расширилась география хоккейных матчей. Помимо Высшей лиги российского чемпионата (КХЛ) на «Матч ТВ» стали освещать матчи Национальной хоккейной лиги (США) и международные соревнования.

В 2015 и 2016 гг. примерно равное эфирное время было отведено телеканалами на освещение боевых искусств (21 бой на «Матч ТВ» и 23 боя на «Россия 2»). Однако к сентябрю 2018 г. телеканал «Матч ТВ» увеличил освещение боевых искусств до 51 трансляции (это было абсолютным показателем), что позволило данному виду спорта стать вторым после футбола.

Что касается волейбола и баскетбола, то здесь больше эфирных событий у «России 2». У «Матч ТВ» этот показатель компенсируется трансляциями других видов спорта, которые на «России 2» абсолютно не освещались. К ним относятся теннис, гребля, мини-футбол, художественная гимнастика, керлинг. За три года показатель трансляций этих видов спорта увеличился относительно общего числа трансляций с 17 до 18,8\%.

Между тем мы можем констатировать, что, несмотря на значительные изменения в эфирной сетке телеканала, аудитория «Матч ТВ» остается довольно скромной по объему, а по сравнению с каналом-предшественником показатели даже понизились. Согласно данным Mediascope ${ }^{8}$, средняя еженедельная доля аудитории (TV Share) телеканала «Россия 2» за 2014 г. составила 2,23\%, в 2015 г. (учитывались данные до 01.11.2015) - 2,44\%. Доля аудитории телеканала «Матч ТВ» в 2016 г. составила 1,84\%, в 2017 г. - 1,77\%, в 2018 г. - 1,9\%9.

\section{Заключение}

После смены владельца и ребрендинга новый спортивный телеканал заполнил эфир контентом исключительно спортивной тематики. Телеканал, как и было заявлено руководством, увеличил количество закупаемых прав на трансляции спортивных событий, а следовательно, и показатель транслируемых спортивных событий. Несмотря на то, что в первый год вещания, телеканал более чем в четыре раза увеличил количество программ, производимых собственными ресурсами, к 2018 г. произошла оптимизация этого показателя, что является закономерной тенденцией для коммерчески ориентированного телеканала. Телеканал «Матч ТВ» в первый год вещания полностью отказался от покупки художественных и документальных фильмов (экономически выгодной модели, при которой при минимальных издержках заполняется эфирное время), однако к 2018 г. телеканал вернулся к закупке фильмов, при этом не нарушив тематически концепцию 
спортивного канала. Отметим, что суще- канала пока не привели к улучшению его ственные изменения в контенте спортивного аудиторных показателей.

\section{Примечания}

1 Что покажет «Матч ТВ»: какие программы телеканал пообещал рекламодателям. 2015. Сент., 30. Режим доступа: https://www.rbc.ru/technology_and_media/30/09/ 2015/560a8e7f9a79476109c3098f

2 Список телеканалов, которые попали под реформирование в рамках создания ГПМ «Матч»: «Россия 2», «НТВ-Плюс Спорт», «Спорт-1», «Спорт-2» (позже «Спорт»), «HD Спорт», «НТВ-Плюс Футбол 1», «НТВ-Плюс Футбол 2», «НТВ-Плюс Футбол 3», «Боец», «Бойцовский клуб», «Наш Футбол», «КХЛ-ТВ», «Конный мир», «НТВ-Плюс Баскетбол», «НТВ-Плюс Теннис».

3 В 2015 г. в рамках ГПМ «Матч» были образованы телеканалы: «Матч ТВ», «Матч! Наш Спорт», «Матч! Арена», «Матч! Игра», «Матч! Футбол 1», «Матч! Футбол 2», «Матч! Футбол 3», «Матч! Боец», «Матч! Наш Футбол», «КХЛ-ТВ», «Конный мир», «Матч! Планета».

4 Телепрограмма. Режим доступа: https://tv.mail.ru/moskva/

5 Передачи текущего сезона. Режим доступа: http://2.russia.tv/brand/

6 Телепередачи. Режим доступа: https://matchtv.ru/programms

7 Толоконникова А.В. (2008) приводит следующую структуру телевизионного дня, ссылаясь на информацию исследовательской компании TNS Gallup Media: paнее утро (7.00-9.00); позднее утро (9.00-13.00); день (13.00-16.00); предпрайм (16.00-19.00); прайм-тайм (19.00-23.00) и постпрайм (23.00-01.00).

${ }^{8}$ Mediascope. Режим доступа: https://mediascope.net/data/

${ }^{9}$ Телевидение в России в 2018 году. Состояние, тенденции и перспективы развития. Режим доступа: http://fapmc.ru/rospechat/activities/reports/2019/teleradio. html

\section{Библиография}

Авдюшкина Я.Д., Аверина М.В. Технологии продюсирования спортивного контента на ЧМ-2018 // Студенческая наука: мат. Межрегиональн. науч. конф., Москва, 27-29 марта 2019 г. М.: РГУФКСМиТ, 2019. С. 327-332.

Белик А.В. Особенности спортивного телерепортажа на примере телеканала «Матч ТВ» // Наследие В.И. Лихоносова и актуальные проблемы развития языка, литературы, журналистики, истории: мат. II Междунар. науч.-практ. конф. Краснодар: Изд-во Фак. журн. Кубанск. гос. ун-та, 2018. С. 235-238.

Вартанова Е.Л. Медиаэкономика зарубежных стран: учеб. пособие. М.: Аспект Пресс, 2003.

Волчков Ф.О. Характеристика концепции современного спортивного телеканала (на примере телеканала «Матч ТВ») // Молодежь XXI века: образование, наука, инновации: мат. VII Всерос. студенческой науч.-практ. конф. с международным участием. Новосибирск: Изд-во Новосибирск. гос. пед. ун-та, 2018. С. 145-147. 
Вьюгина Д.М. Цифровые стратегии медиабизнеса в условиях изменяющегося медиапотребления // Медиаскоп. 2016. Вып. 4. Режим доступа: http://www.mediascope. $\mathrm{ru} / 2233$

Долгова Ю.И. Принципы программирования тематического телевидения: «Москва 24» «канал к завтраку» // МедиаАльманах. 2017. № 5. С. 87-96.

Павлов А.С. Телеканал «Матч ТВ» в системе российского спортивного телевидения: своеобразие контента // Проблемы гуманитарного образования: филология, журналистика, история: сб. науч. ст. III Междунар. науч.-практ. конф. Пенза: Изд-во Пензенск. гос. ун-та, 2016. С. 138-140.

Толоконникова А.В. Особенности программирования «Первого канала» // Медиаскоп. 2008. Вып. 2. Режим доступа: http://www.mediascope.ru/issues/150?page=1

Eastman, S.T., Ferguson D.A. (2012) Media Programming: Strategies and Practices. $9^{\text {th }}$ ed. Boston: Wadsworth Publishing.

Evens T., Iosifidis P., Smith P. (2013) The Political Economy of Television Sports Rights. Palgrave Macmillan UK. 